\title{
Gillnet selectivity of the Indian oil sardine Sardinella longiceps fished in the Sea of Oman
}

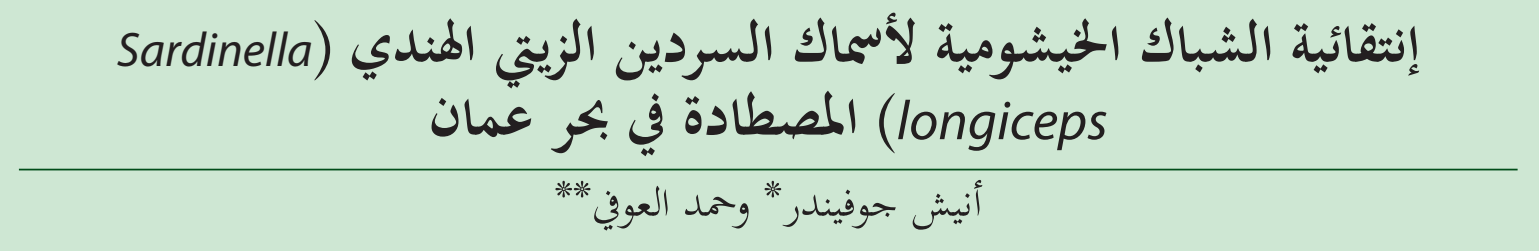

AbStract. The size selectivity of drift gill-nets for Sardinella longiceps was investigated in the Sea of Oman using a range of 5 nets between 3.3 and $5.7 \mathrm{~cm}$ stretched mesh size. All nets had a hanging ratio of 0.5 . A total of 1211 Indian oil sardines were caught in the 5 experimental nets, the majority of which were retained by the $3.3,3.8$ and $4.5 \mathrm{~cm}$ mesh nets. Peak selectivity was reached at $14.9 \mathrm{~cm}$ FL for the $3.3 \mathrm{~cm}$ mesh size increasing to $16.9 \mathrm{~cm}$ for the $3.8 \mathrm{~cm}$ mesh size. The estimated and observed length frequency distributions were unimodal. A log-normal selection function indicated that the highest selectivity was obtained when the length class to mesh size $(\mathrm{l}: \mathrm{m})$ ratio was 4.4. Sardinella longiceps's relative abundance was estimated to be the highest at $16.4 \mathrm{~cm} \mathrm{FL}$, with numbers decreasing beyond this peak. This would indicate that selectivity by gilling is optimal with a mesh size of $3.8 \mathrm{~cm}$ with nets having a hanging ratio of 0.5 . This mesh size appears to satisfy two criteria: high catch efficiency and protection of juveniles.

KEYwOrDS: Sardine; gillnet selectivity; model; Sea of Oman.

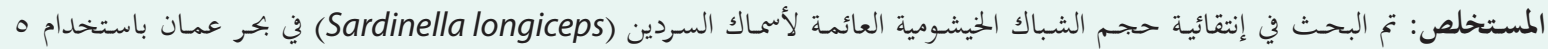

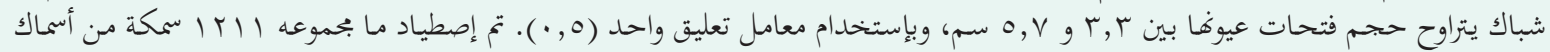

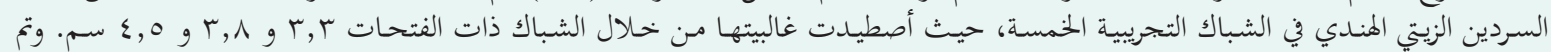

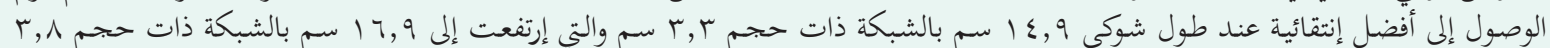

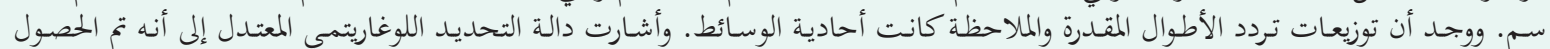

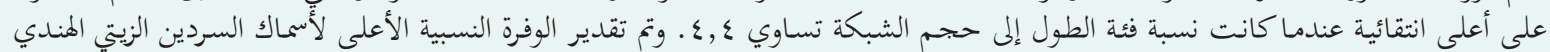

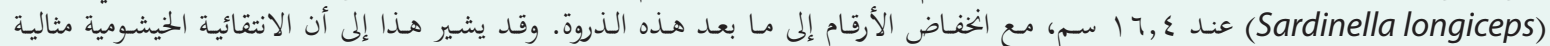

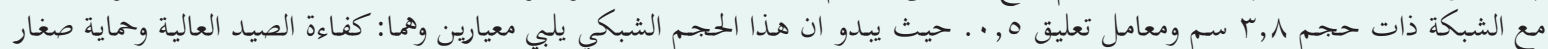

$$
\begin{aligned}
& \text { الأسماك الثن. } \\
& \text { الكلمات المفتاحية: السردين، إنتقائية الشباك الخيشومية، نموذج، بحر عمان }
\end{aligned}
$$

\section{Introduction}

G illnet selectivity is the quantitative measure of the amount of fish caught within a size range that is retained by the net and it is a function of the probability of the fish encountering the net, the chance of being caught and the intensity of the fishing. Generally, one length class will be sampled most efficiently with efficiency decreasing symmetrically to zero both above and below this length class. Because gillnets are highly selective for fish of certain sizes, knowledge of the selection is necessary for both population assessment and management of the fishery (Carlson and Cortés, 2003). Selection curves can be used to set a mesh size that can restrict the size of fish captured and hence,

Govender, Anesh ${ }^{*}(\square)$ Department of Marine and Fisheries Science, College of Agricultural and Marine Sciences, Sultan Qaboos University, P.O. Box 34, Al-Khoud 123, Sultanate of Oman

** Ministry of Agriculture and Fisheries, Sultanate of Oman, P. O. Box 427, Muscat, Postal Code 100

"Corresponding author: govender@squ.edu.om limit the catch of immature fish or reinforce minimum landing size regulations. In this study we describe the selection curve of the Indian oil sardine (Sardinella longiceps) harvested in the Sea of Oman.

The Indian oil sardine is found in the north and west Indian Ocean ranging from the horn of Africa, along the Arabian Sea, Sea of Oman and Aden (excluding the Red Sea and Arabian Gulf) and then eastward to the southern coasts of India and Sri Lanka (Al-Abdessalaam, 1995). Small pelagic fish, including S. longiceps, occur in abundance in Omani waters.

This species forms an important component of the marine food web because it comprises the bulk of the forage for large fish and other predators (Al-Barwani et al., 1989). The Indian oil sardine and other sardines also contribute significantly to the Omani marine fishery. In 2013 about 52544 tonnes of sardines were landed along the coast of Oman, of which 8320 (16\%) tonnes were $S$. longiceps (Anonymous, 2013).

This species, as well as other sardines, is exploited 
Table 1. Estimates and their 95\% confidence intervals for the parameters of the selection equation for three mesh sizes (3.3, 3.8 and $4.5 \mathrm{~cm}$ stretched mesh) with a hanging ratio $=$ 0.5. The negative $\log$-likelihood $(\log L)=-4345.944$.

$\begin{array}{ccc}\text { Parameter } & \text { Value } & \text { 95\% Confidence Interval } \\ k & 4.4 & 4.3-4.5 \\ \sigma & 0.124 & 0.117-0.133\end{array}$

primarily by cast nets, beach seines and gillnets. As they require little investment in manpower and equipment, and are efficient in catching pelagic fish, gillnets are widely used by traditional Omani fishermen. Because of the decline in large pelagics (e.g. Scomberomorus commerson (Govender et al., 2006), human consumption of sardines has increased, resulting in increased market prices. These issues will likely result in over-exploitation of sardines which may lead to a decrease in abundance in the future. Based on late 1980s data, (Dorr, 1991) already observed that sardines were caught at near optimum levels. Although fluctuations in sardine abundance are largely regulated by the environment (Kawasaki, 1991), intensive fishing in coastal waters may reduce fish productivity.

Seeing as the Indian oil sardine is considered one of the key species in the Oman fishery, selectivity estimates are potentially of great value in management and research. Therefore, the main objective of this study was to determine the gillnet selection parameters of the Indian oil sardine gillnet using nets of different mesh sizes fished simultaneously on the same population.

\section{Materials and Methods}

Sampling was carried out monthly between September 2001 and July 2003 on board the RV Al-Jamiah, a $17.5 \mathrm{~m}$ (overall length) multipurpose fishing boat. Green polyamide (nylon) gillnets of similar thickness (PA 210D $\times$ 6 plays) and of mesh sizes 3.3, 3.8, 4.5, 5.0 and $5.7 \mathrm{~cm}$ (stretched mesh) were used. For each mesh size a gillnet was constructed with 0.5 hanging ratio; thus 5 experimental nets of similar fishing power were constructed and joined together as a gang. For all nets, a similar hanging ratio was used for the float line and the lead line to restrict fish being tangled. All nets were made to the same finished length of $25 \mathrm{~m}$, giving a total length of 125 $\mathrm{m}$ and a fishing height of $3 \mathrm{~m}$. The nets were rigged with a $6 \mathrm{~mm}$ PE (polyethylene) float line fitted with several PVC floats (113 g buoyancy) regularly distributed to give a float line buoyancy of around $135 \mathrm{~g} / \mathrm{m}$, while the sinking force employed for the lead lines had a force of 50 $\mathrm{g} / \mathrm{m}$. The order of mesh panels was randomized at the beginning of the experiment. The nets were joined together with a $2 \mathrm{~m}$ gap between adjacent nets. This design was chosen to avoid the effect of larger fish being led by smaller mesh-sized nets into neighboring nets of a more suitable mesh size (Hovgård, 1996; Madsen et al., 1999). Each net was coded to enable identification on hauling.
Fishing stations were selected in shallow waters in the Muscat $\left(23^{\circ} 37^{\prime} \mathrm{N}, 58^{\circ} 35 \mathrm{E}^{\prime}\right)$ area. One end of the net series remained attached to the boat by a rope and both the net and boat was set to drift with the current. Fishing was carried out a few hours before sunrise and the net series was hauled-in after sunrise giving an average fishing time of 4 hours. The total number of valid sets was 34.

Catches were sorted by species and fork length (FL) was measured to the nearest $\mathrm{cm}$ and the weight to the nearest gram. Girth measurements at the snout, behind the head and at maximum girth (before the dorsal fin) were also recorded for each fish. Although girth measurements were taken for all fish, fork length was used to construct the selectivity curves because length is closely related to mesh size as is girth (Reis and Pawson, 1999). Gilled or wedged fish were used in the analysis while tangled fish were excluded from the analysis as tangling of fish is not a function of net selectivity.

\section{Selectivity modeling}

Hamley (1975) provided a review of the approaches to estimate gillnet selection curves and more recently Hovgård and Lassen (2000) provided an updated review of all methods, including new statistical approaches that are based on general models for the selection process.

$$
\hat{C}_{l, m}=\left(q N_{l} S_{l, m}\right)+\text { error }
$$

The parameters for the selection curves in this study were obtained using maximum likelihood (ML) (Kirkwood and Walker, 1987; Millar, 2000). Assuming that fishing effort and fishing power are constant, the selection equation (Hovgård and Lassen, 2000) is written as

$$
S_{l, m}=\exp \left[-0.5\left(\ln \left(\frac{l}{m}\right)-\ln k\right)^{2} / \sigma^{2}\right] \quad \text { Eq. } 2
$$

where-?-is the predicted catch in length class $l$ for mesh size $m, q$ is the catchabilty co-efficient (assumed constant for each $l$ and each $m$ ), $N$ is the number of available fish and $S$ is the selectivity function. We assumed that the selectivity function followed a log-normal distribution i.e.

$$
\text { error }=\left[\frac{\left(\hat{C}_{l, m}\right)^{C_{l, m}}}{C_{l, m} !} \exp \left(\hat{C}_{l, m}\right)\right] \quad \text { Eq. } 3
$$

and that the error was Poisson distributed i.e. where $C$ is the observed catch, $\mathrm{k}$ is the predicted ratio of $(\mathrm{l} / \mathrm{m})$ that has the maximum selectivity and $\sigma$ is the dispersion factor around $k$. 


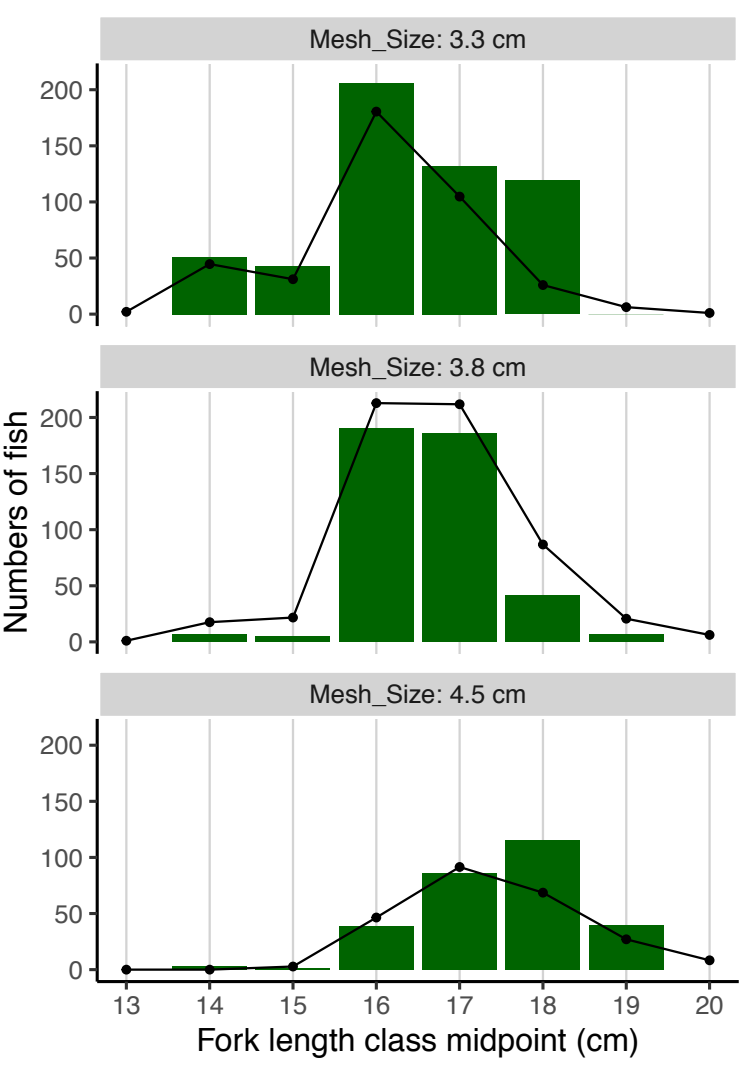

Figure 1. Observed (bars) and predicted (lines) numbers of Sardinella longiceps caught with gillnets of varying mesh sizes.

$-\log (L)=\sum_{l} \sum_{m}\left[C_{l, m} \ln \left(\hat{C}_{l, m}\right)-\hat{C}_{l, m}\right] \quad$ Eq. 4

The estimates of the parameters $\mathrm{k}$ and $\sigma$ were obtained by minimizing the negative of the log-likelihood $(\log L)$, with constant values removed.

The 95\% confidence intervals for the parameters $\mathrm{k}$ and $\sigma$ were obtained using the likelihood ratio test (Lebreton et al., 1992).

\section{Results}

A total of 1211 Indian oil sardines were caught in the 5 experimental gillnets, the majority of which were retained by the 3.3 (454), 3.8 (438) and $4.5 \mathrm{~cm}$ (301) nets. Because catches obtained with the 5.0 (17) and the 5.7 $\mathrm{cm}$ (1) meshes were small, these data were not included in the analysis. Almost all S. longiceps caught (gilled or wedged) were observed to have meshes stretched tight across their bodies in the region behind the gill cover to the maximum girth. Some were observed to have twine caught in their mouth (snagged) and some others were entangled. Only the first category was included in the analysis, although the other two categories do not appear to affect their size selection as length distributions were similar for all three categories of entrapment in the nets.

As expected, the mode of the length frequency distribution of S. longiceps for different mesh sizes increased with mesh size (Fig. 1). The observed peak length for the 3.3, 3.8 and the $4.5 \mathrm{~cm}$ mesh gillnets were 16.1, 16.5 and $18.0 \mathrm{~cm}$, respectively. The size range of fish caught by the $3.3 \mathrm{~cm}$ mesh size was 13-18 cm, compared with 14-19 $\mathrm{cm}$ for the $3.8 \mathrm{~cm}$ and $14-20 \mathrm{~cm}$ for the $4.5 \mathrm{~cm}$ mesh size (Fig. 1). The length distributions were unimodal except for the $3.3 \mathrm{~cm}$ mesh size which showed a second minor mode at $14 \mathrm{~cm}$ FL (Fig. 1)

\section{Gill net selectivity}

The estimated selectivity curves for S. longiceps appeared bell-shaped (Fig. 2), which is to be expected for fish that are gilled or wedged, as was confirmed during fishing trials. Peak selectivity was reached at $14.9 \mathrm{~cm}$ FL for the $3.3 \mathrm{~cm}$ mesh size, increasing to $16.9 \mathrm{~cm}$ for the $3.8 \mathrm{~cm}$ mesh size. The results indicated that the 3.3 and $3.8 \mathrm{~cm}$ mesh size had an equal selectivity for fish of $15.8 \mathrm{~cm}$ in length, whereas the 3.8 and the $4.5 \mathrm{~cm}$ mesh sizes had an equal selectivity for fish of $18.3 \mathrm{~cm}$ length (Fig. 2). The estimated parameter values and their $95 \%$ confidence intervals are given in Table 1. Maximum selectivity was achieved at an $l: m$ ratio of 4.4 (Table 1). The small confidence intervals indicate that the parameters are well estimated (Table 1).

\section{Discussion}

There has been no previous attempts to estimate gillnet selectivity parameters for the Indian oil sardine and hence, comparisons cannot be made. The unimodal nature of the selection curve is linked to the catching process, namely gilling or wedging, whereas maxillae enmeshing or entangling, which would have resulted in either a sigmoid-shaped or a bimodal curve, was shown to have been of little importance. Since the Indian oil sardine has no spines or any other projections on its body which could result in entanglement the shape of the selection curve is therefore influenced by fish girth alone. Girth being directly proportional to fish length justifies the latter being used as a proxy for girth since fish length is easier and quicker to measure. These findings are in agreement with those of Reis and Pawson (1999) and Santos et al. (1998), although both these studies were investigating other fish species; they had similar body shapes to $S$. longiceps. In contrast, several studies have used bimodal selection curves with two distinct modes that are linked to two different catching processes, wedging and entangling (Madsen et al., 1999). Millar and Fryer (1999) used a bimodal selection curve to describe plaice catch data in a trammel net experi- 


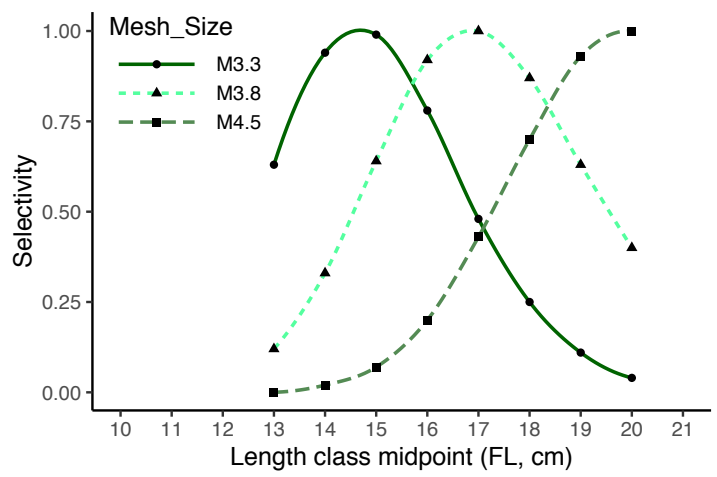

Figure 2. Selectivity curves for various mesh sizes for Sardinella longiceps. The plotted lines have been smoothed.

ment while Madsen et al. (1999) used it for sole, plaice and cod and Hovgård (1996) used it for cod catch data. While our data did showed a minor mode for the $3.3 \mathrm{~cm}$ mesh net we regarded it as negligible for the model fitting process.

Previous studies have indicated that $S$. longiceps reaches first maturity at $15.93 \mathrm{~cm}$ total length in the Sea of Oman (Siddeek et al., 1994). This total length was transformed to a fork length using the equation:

$$
T L=1.075 F L+0.72
$$

Eq. 5

$\mathrm{R}^{2}=0.96(\mathrm{H}$. Al-Oufi, unpubl. data).

Length at first maturity for this population is therefore equal to $14.1 \mathrm{~cm}$ FL. The length at first maturity is slightly lower than the optimal catch size computed for the $3.3 \mathrm{~cm}$ mesh size. In catches of the $3.3 \mathrm{~cm}$ gillnet, individuals under the length at first maturity made up slightly more than $11 \%$ of the catch, whereas this was around $2 \%$ for the $3.8 \mathrm{~cm}$ gillnet and was virtually zero for the $4.5 \mathrm{~cm}$ mesh. Although, a minimum landing size has not yet been set for S. longiceps in the Omani fishery, the results of this study show that in the interests for sustainable fishing of $S$. longiceps it can be suggested that gillnets with stretched mesh of $3.8 \mathrm{~cm}$ (with a hanging ratio $=0.5$ ) should be used. This would certainly increase the average size caught when compared to the $3.3 \mathrm{~cm}$ net. Catches obtained with the $4.5 \mathrm{~cm}$ gillnet were always small, confirming that the large mesh size targeted only the larger individuals of the Indian oil sardine population in the Sea of Oman. The $3.8 \mathrm{~cm}$ mesh size gillnet appears to satisfy two criteria: high catch efficiency and protection of juveniles.

The use of smaller mesh sizes in this experiment may have resulted in a better match between the overall selectivity of the gang of nets and the relative Indian oil sardine population abundance. However, it was considered more important to include those mesh sizes that have direct applicability to gillnets used by local fishers. Construction details of nets used in this study, such as twine diameter and hanging ratio, is similar to that used by the local fishers (Stengel and Al Harthy, 2002).

The shape of the selectivity curve depends on several characteristics of the fish and the net. Gray et al. (2005) reported an overall reduction in mean catch associated with an increased hanging ratio, although the results were not significant. Of particular importance are the physical properties of the twines used, such as extensibility and elasticity (Klust, 1982). Low extensibility and elasticity result in the loss of captured fish which ultimately will influence the estimated selectivity. The twines used to construct the experimental gillnets were polyamide continuous filaments, which has high extensibility coupled with high elasticity. Reported elasticity was above 96\% (Klust, 1982) which means that these twines are almost completely elastic, a property that is needed to hold the gilled fish securely while the gear is in the catching process and during hauling (Klust, 1982). Other factors, such as sex, ripeness and amount of food in the gut, would also influence the girth of the fish and hence the shape of the selectivity curves. To minimize variation caused by reproduction and gut contents, (Salvanes, 1991) proposed pooling samples for months when food availability and temperature are the lowest. This could not be achieved in this study as this would have reduced sample sizes to unacceptably low numbers. Márquez-Farias et al. (2005) added oceanographic currents as a possible factor affecting selectivity; since strong currents can distort the shape of the meshes and therefore select for fish sizes not captured under conditions of a mild current. This effect was considered negligible in this study.

There are limitations to this study. The study was limited to the Muscat area (for logistic reasons) and since sardines generally school and migrate in similar age/ length classes it is quite possible that smaller/younger or larger/older classes were not available for capture. This research need should be accounted for in future research.

\section{Acknowledgement}

The authors express sincere thanks to Prof. Anton MacLachlan, former Dean of the College of Agricultural and Marine Sciences, Sultan Qaboos University who kindly reviewed the manuscript and to Dr. Michel Claereboudt of Sultan Qaboos University who assisted with the ML model and provided many comments and suggestions. Sincere thanks to Mr Khamis Al-Riyami, Saleh Al_Mashari, Manolito C. Barte and Mohamed AlGhithy who assisted during the fishing operations. This study was funded by Sultan Qaboos University (Project Number: IG/AGR/FISH/00/03)

\section{References}

Al-Al-Abdessalaam, T.Z.S., 1995. Marine Species of the Sultanate of Oman. Muscat: Marine Science and Fisheries Centre, Ministry of Agriculture and Fisher- 
ies. 412 p.

Al-Barwani M, Prabhakar A, Dorr J, Al-Manthery M., 1989. Studies on the biology of Sardinella longiceps (Valenciennes) in the Sultanate of Oman, 1985-1986. Kuwait Bulletin of Marine Science 10,201-209.

Anonymous, 2013. Annual Fisheries Statistical Year Book for 2013. Muscat: Ministry of Agriculture and Fisheries Resources.

Carlson, J.K., Cortés E. 2003. Gillnet selectivity of small coastal sharks off the southeastern United States. Fish Res 6,:405-414.

Dorr, J.A., 1991. Small pelagics final report for the contract for technical services for staffing the Marine Science and Fisheries Center. Project No 272-01011-1.

Gray, C.A., Broadhurst, M.K., Johnson, D.D., Young, D.J., 2005. Influences of hanging ratio, fishing height, twine diameter and material of bottom-set gillnets on catches of dusky flathead Platycephalus fuscus and non-target species in New South Wales, Australia. Fish Sci 71,1217-1228.

Hamley, J., 1975. Review of gillnet selectivity. J Fish Res Board Can 32,1943-1969.

Hovgård. H., 1996. A two-step approach to estimating selectivity and fishing power of research gill nets used in Greenland waters. Can J Fish Aquat Sci 53,10071013.

Hovgård, H, Lassen, H. 2000. Manual on estimation of selectivity for gillnet and longline gears in abundance surveys. Rome: FAO.

Kawasaki, T. 1991. Long-term variability in the pelagic fish population. In: Kawasaki, T., Tanaka, S., Tola, Y., Taniquiche, A., editors. The long-term varaiability of pelagic fish populations and their environment. New York: Pergamon Press.

Kirkwood, G.P., Walker, T.I. 1987. Gill net mesh selectivities for gummy shark, Mustelus antarcticus Günther, taken in south-eastern Australian waters. Aust J Mar Freshw Res 37,689-697.

Klust, G. 1982. Netting materials for fishing gear. Rome:
FAO. 175 p.

Lebreton, J.D., Burnham, K.P., Clobert, J, Anderson, D.R., 1992. Modeling survival and testing biological hypotheses using marked animals: A unified approach with case studies Ecol Monogr 62,67-118.

Madsen, N., Holst, R., Wileman, D., Moth-Poulsen, T., 1999. Size selectivity of sole gill nets fished in the North Sea. Fish Res 44,59-73.

Márquez-Farias, J.F., Corro-Espinosa, D., CastilloGéniz, J.L., 2005. Observations on the biology of the Pacific sharpnose shark (Rhizoprionodon longurio, Jordan and Gilbert, 1882), captured in southern Sinaloa, México. Journal of Northwest Fishery Science 35,107-114.

Millar, R.B., 2000. Untangling the confusion surrounding the estimation of gillnet selectivity. Can J Fish Aquat Sci 55,1328-1337.

Millar, R.B., Fryer, R.J., 1999. Estimating the size-selection curves of towed gears, traps, nets and hooks. Rev Fish Biol Fish 9, 89-116.

Reis, E.G, Pawson, M.G., 1999. Fish morphology and estimating selectivity by gillnets. Fish Res 39,263-273.

Salvanes, A.G.V., 1991. The selectivity for cod (Gadus morhua) in two experimental trammel-nets and one gillnet. Fish Res 10,265-285.

Santos, M.N., Monteiro, C.C., Erzini, K., Gerard, L., 1998. Maturation and gill-net selectivity of two small sea breams (genus diplodus) from the Algarve coast (South Portugal). Fish Res 36,185-194.

Siddeek, M.M., Al-Habsi, H.N., Al-Jufaily, S.M., Al-Ghafry, I.N., 1994. Spawning cycle, recruitment patterns and maturity length of Indian Oil sardine at Al-Aziba, the Sea of Oman. In: Chou, L.M., Munro, A.D., Lam, T.J., Chen, T.W., Cheong, L.K.K., Ding, J.K., Hooi, K.K., Khoo, H.W., Phang, V.P.E., Shim, K.F., Tan, C.H., editors. The Third Asian Forum. Manila, Philippines: Asian Fisheries Society.

Stengel, H., Al Harthy, A., 2002. The traditional fishery of the Sultanate of Oman (fishing gear and methods). Muscat: Ministry of Agriculture and Fisheries, Directorate General of Fisheries Resources, Marine Science and Fisheries Center. 147 p. 